\title{
O papel do laboratório didático na visão de mestrandos em ensino de ciências
}

\section{The role of the didactic laboratory in science education master's degree students view}

\author{
${ }^{1}$ Marcus Vinicius Pereira marcus.pereira@ifrj.edu.br \\ ${ }^{1}$ Maria Cristina do Amaral Moreira
}

\section{RESUMO}

O presente estudo procurou entender a relação entre a epistemologia e a pedagogia do laboratório didático na visão de mestrandos em ensino de ciências. Foram investigadas as concepções desses estudantes sobre o papel do laboratório didático, as atividades realizadas nele e a sua contribuição para o processo de ensino e aprendizagem. A partir do referencial da análise do discurso e de três modelos teóricos básicos de epistemologias da ciência de Zimmermann, o estudo, de natureza qualitativa, categorizou as falas dos sujeitos da pesquisa de acordo com duas visões sobre as relações entre natureza da ciência e o processo de ensino e aprendizagem de ciências. Foram identificados ambivalências e contrapontos que apontam para formas não tão universalistas de entender a ciência.

Palavras-chave: Laboratório didático. Atividade prático-experimental. Epistemologia da ciência; ensino de ciências.

\begin{abstract}
The present study sought to understand the relationship between the epistemology and the pedagogy of didactic laboratory in science education master's degree students view. The students' conceptions of the role of the didactic laboratory, the activities carry out in it and their contribution to the teaching-learning process were investigated. In a qualitative way, from the discourse analysis framework, we have adapted Zimmermann theoretical model in order to categorize the students' speeches according to two views on the relations between nature of science and science teaching-learning process. Ambivalences and counterpoints have been identified which point to non-universalist ways of understanding science.
\end{abstract}

Keywords: Didactic laboratory. Practical-experimental activity. Science epistemology; science education. 


\section{INTRODUÇÃO}

Desde a gênese da área de pesquisa em ensino de ciências em meados do século XX, o papel das atividades prático-experimentais na escola vem sendo investigado sob diferentes perspectivas ao longo dos anos. O laboratório escolar, além de constituir um espaço físico (muitas vezes inexistente) onde se realizam ações voltadas ao ensino de ciências, constitui também uma forma de se pensar o ensino de ciências. Nesse sentido, considerando as distintas epistemologias da ciência, analogamente profissionais da educação entendem de forma diversa o papel do laboratório para o ensino. Há desde aqueles que, ao se referirem ao uso do laboratório, afirmam realizar atividades experimentais, até aos que consideram esse espaço como oportuno para realização de atividades práticas, simulações, entre outros. Destacamos ainda certa polissemia ao se pensar no papel do laboratório de ciências, tanto na academia como no cotidiano escolar (PEREIRA e MOREIRA, 2017).

Portanto, nessa investigação, buscamos identificar as diferentes concepções sobre as atividades prático-experimentais, categorizando-as em discursos ${ }^{2}$ que compreendem bases epistemológicas de saberes sobre as ciências no contexto escolar. Como apontamos anteriormente, o laboratório didático é um recorrente objeto de pesquisas da área de ensino de ciências, em que se destaca a reflexão sobre a sua-contribuição para o processo de ensino e aprendizagem (LUNETTA, HOFSTEIN, e CLOUGH, 2007).

Marandino, Selles e Ferreira (2009, p.107) apontam a dimensão cultural e histórica do que entendem por experimentação didática ao refletirem sobre o laboratório escolar de ciências / biologia, afirmando que a experimentação didática

acompanha tradições, mas sofre transformações em resposta às finalidades escolares historicamente consideradas. Nesta instituição às finalidades não são a de formar biólogos, e sim proporcionar a todos os alunos vivências culturais criativas por meio das atividades experimentais que os ajudem a fazer relações com os conhecimentos escolares.

Com a criação da área de Ensino no Brasil em 2000 (denominada Ensino de Ciências e Matemática até 2011), houve um crescimento exponencial no número de cursos de mestrado (acadêmico e profissional, sobretudo esse último), de forma que as pesquisas, antes centradas mais no aluno e no professor passaram a se debruçar sobre a visão de pós-graduandos, muitos com experiência docente no ensino básico ou atuando, de alguma forma, no processo educativo.

Sendo assim, é relevante compreender, a partir dos saberes docentes/profissionais de alunos cursando mestrado, a necessidade de pensarmos em práticas de formação continuada que estabeleçam diálogo entre as correntes teóricas do ensino de ciências e os saberes que circulam em diferentes espaços de formação. Portanto, problematizamos o papel do laboratório didático naquilo que é sua função no ensino de ciências presente na escola, de forma a entender porque certas práticas permanecem, se reinventando, em detrimento de outras, menos presentes, ou seja, mais silenciadas.

Neste artigo, partimos do entendimento de que atividades prático-experimentais compreendem um conjunto de ações realizadas de forma intencional para ensinar algo. Além disso, correspondem à experimentação no âmbito da ciência, mas não ressignificada da mesma forma na escola. Trata-se de atividades que se aproximam de uma investigação científica na busca de responder a um questionamento e que, para além das ações envolvidas na atividade, levam a um ensino de ciências que compreenda uma "estrutura curricular de disciplinas de conteúdo específico de modo que enfatizem não somente o conhecimento específico, mas também a fenomenologia e a transposição didática” (SILVA, MOHR e ARAÚJO, 2012, p.10). Dessa forma, atividades prático-experimentais possibilitam a participação ativa do aluno e do professor, incluindo desde a experimentação com aparatos, vidraria e objetos, à construção de modelos e estudo do meio, inclusive podendo envolver a exibição e/ou a produção de audiovisual, simulação, jogo, entre outros (PEREIRA e MOREIRA, 2017). Por isso, neste estudo objetivamos interpretar essas atividades na sua pluralidade metodológica, buscando perceber, na relação entre a epistemologia e a pedagogia, como essas propostas de laboratório,

2 Discurso no seu caráter semiótico e não só como texto escrito. 
isoladas ou articuladas, produzem sentido para o meio escolar. O interesse específico da pesquisa foi o de mapear as significações para as atividades didático-pedagógicas nas respostas dadas por profissionais, discentes de um curso de mestrado da área de ensino de ciências, além de compreender os limites apontados pelos mestrandos sobre a realização de algumas dessas atividades no ensino de ciências.

\section{REFERENCIAL TEÓRICO}

Compreender o lugar do laboratório escolar de ciências (sob as diversas atividades prático-experimentais que, nesse espaço, podem ser desenvolvidas) a partir dos estudos críticos é, sobretudo, procurar entender as relações de poder entre discursos, nesse caso, aqueles pertencentes a outras práticas sociais incorporadas ou em interseção com a escola, tais como os da ciência, da política, da mídia, do senso comum etc. Assim, a partir de representações discursivas, é possível problematizar o laboratório como uma questão do ensino de ciências. O discurso da ciência na escola é recontextualizado em documentos e práticas, no livro didático, nas avaliações, no laboratório escolar, entre outros e, embora haja discursos hegemônicos sustentando relações de dominação no que tange ao laboratório escolar (corroborar uma teoria, aprender um conceito etc.), alguns podem incluir mudanças dessas relações (FAIRCLOUGH, 2001).

Para essa pesquisa, partimos dos modelos de natureza da ciência propostos por Zimmermann (2000), entendidos aqui como discursos, para, dessa forma, identificar epistemologias presentes nas concepções de laboratório expressas pelos mestrandos participantes desta pesquisa. Entendemos que, no que diz respeito ao currículo da ciência escolar, a ciência vem sendo apresentada

numa perspectiva internalista, com a crença em um ideal científico universal e independente da história de cada civilização. Ideal este profundamente marcado pelo iluminismo ocidental, que, como mostra Said (1990), encontra-se fortemente vinculado a uma tradição que o eixo Europa-EUA tornou hegemônica. Retomar a advertência de McCarthy (1994) e analisar as formas como se estabelecem as relações entre a "cultura iluminista” e os outros sistemas de conhecimento parece-me relevante para um projeto de educação multicultural. (MACEDO, 2004, p.106)

Segundo Macedo (2004), ao se referir sobre o estudo dos livros didáticos de ciências, há uma corporificação de certas formas culturais (hegemônicas) de entender a ciência em detrimento de outras mais marginalizadas. Já para Zimmermann (2000), os modelos de natureza da ciência nem sempre impactam as formas com que professores ensinam ciências, uma vez que eles podem ter concepções “mistas ou ecléticas”. Ensinar ciências depende da forma como aquele que ensina vê a produção do conhecimento científico. Portanto, há vários modelos de ensinar e aprender ciências, mesmo que os professores tenham formação e contextos de atuação semelhantes.

Nesse sentido, estabelecemos três eixos teóricos para análise - (i) a natureza da ciência e o papel do laboratório, (ii) a visão de ensino e aprendizagem e (iii) o papel das atividades prático-experimentais - sob duas visões (I e II), que se encontram resumidos no Quadro 1 abaixo.

Quadro 1: Eixos teóricos para análise das respostas dos mestrandos sobre o laboratório.

\begin{tabular}{|c|c|c|}
\hline EIXO & VISÃo I & VISÃo II \\
\hline Natureza da ciência e o laboratório & $\begin{array}{c}\text { Indutivo / Método científico único } \\
\text { Comprovação / Demonstração }\end{array}$ & $\begin{array}{c}\text { Métodos científicos / Diversidade } \\
\text { Investigação / Coletivo }\end{array}$ \\
\hline Visão de ensino e aprendizagem & Comportamentalista / Behaviorista & Construtivismo / Plural \\
\hline Papel das atividades prático- & $\begin{array}{c}\text { Lúdica: motivar, despertar interesse, } \\
\text { facilitar, aproximar, potencializar }\end{array}$ & $\begin{array}{c}\text { Racional: desenvolver modelos, } \\
\text { aprender a teoria, relacionar } \\
\text { teoria e prática, abstração }\end{array}$ \\
\hline
\end{tabular}

Fonte: adaptado de Zimmermann (2000). 


\section{METODOLOGIA}

Neste estudo, de natureza qualitativa, utilizamos a análise do discurso, sob a qual se entende que a linguagem é multifuncional e, portanto, todo texto apresenta funções, tais como a ideacional, a interpessoal e a textual. A análise que desenvolvemos, mesmo entendendo que a linguagem não pode prescindir de uma dessas funções, se limitou a dimensão ideacional. Essas funções possibilitam olhar para o texto (respostas dos sujeitos) como construção da realidade social (FAIRCLOUGH, 2001).

A coleta de dados ocorreu por meio da aplicação de um questionário a sete alunos no início da primeira aula de uma disciplina de um curso de mestrado dedicada a pensar o laboratório no ensino de ciências, antes de qualquer discussão formal. Esse curso, com duração máxima de 24 meses e previsão de prorrogação de até seis meses, tem por base duas linhas de pesquisa (formação de professores de ciências e reflexões sobre o ensino de ciências na contemporaneidade), e apresenta oito disciplinas obrigatórias de dois créditos cada uma (30 horas), sendo a disciplina em que desenvolvemos a pesquisa, uma delas, e os autores desse artigo, os docentes responsáveis. Além disso, cada mestrando deve cumprir dez créditos em disciplinas eletivas.

Em geral, os alunos de cursos de mestrado da área de ensino de ciências são licenciados em biologia, física, matemática ou química, mas, algumas vezes, há também profissionais de outras áreas (pedagogia, comunicação, história etc.). Nesse grupo, quatro mestrandos têm formação inicial em ciências biológicas, um em física, um em química e um em história (que trabalha na área de divulgação científica em um centro de ciências). Ainda que o curso não seja da modalidade profissional, todos os alunos exercem a função de docente, o que leva a crer que suas respostas expressam ideias baseadas nas experiências que tiveram como alunos e professores da escola básica, já que nenhum deles tinha qualquer experiência em formação continuada.

Como instrumento de pesquisa, temos um questionário (previamente validado em turmas anteriores) que contém três indagações, a saber: (1) Qual o papel de um laboratório didático de ciências? (2) Que tipos de atividades podem ser realizadas em um laboratório de ciências? (3) Qual o papel dessas atividades, ou seja, como elas podem contribuir com o processo de ensino e aprendizagem? Todos os requisitos relacionados à ética no que tange à realização de pesquisas envolvendo seres humanos foram atendidos, e cada sujeito concordou em participar deste estudo por meio da assinatura de um termo de consentimento livre e esclarecido.

\section{RESULTADOS E DISCUSSÃO}

As falas de cada mestrando, designado pela letra $\mathrm{M}$ seguida de um algarismo de 1 a 7 , foram analisadas a partir do referencial da análise do discurso de Fairclough (2001) e de três modelos teóricos básicos de epistemologias da ciência (Quadro 1) adaptados de Zimmermann (2000). De uma maneira geral, as respostas demonstraram que, ao serem questionados sobre laboratório didático, os mestrandos apontam, sobretudo, aspectos pedagógicos em relação aos da ciência, evidenciando que o saber pedagógico tem valor se comparado aos disciplinares, ou seja, o como ensinar sobressai em relação ao que ensinar. No entanto, quando questionados especificamente sobre o papel do laboratório, ainda persistem ideias hegemônicas como nos excertos a seguir.

Deve propiciar uma vivência do alunado em práticas que condizem com o que o professor trabalhou na sala de aula. (M2)

Para reforçar ou apresentar um conteúdo para os alunos, usando equipamentos, materiais e métodos científicos. (M3) 
No que diz respeito às concepções do papel do laboratório didático, a visão de comprovação e de demonstração ainda se apresenta enraizada nas respostas desses mestrandos. Identificamos o binômio teoria-prática em um sentido de que a teoria precede a prática, como no exemplo acima na resposta de M3 e também na resposta de M1 ao afirmar que "Realizar conexões com os conteúdos teóricos”. A partir das respostas, pudemos também inferir que o objetivo do laboratório ultrapassa a questão da ciência, já que ciência é parte obrigatória no ensino de ciências, o que significa que o enfoque dado pelos mestrandos é no reforço do que foi ensinado na sala de aula (trabalhado, conteúdo, abstrato), se constituindo como mais uma possibilidade dos alunos apreenderem - o que se enquadra na Visão I do primeiro eixo teórico (Quadro 1). Por outro lado, a Visão II aparece mesclada com a concepção indutivista de ciência nas respostas de M2 e M5.

Colabora para um aprendizado construtivo e autônomo do aluno, o qual tem grande ênfase no método cientifico. (M2)

Favorecem a realização de atividades práticas e ou coletivas; diversificam o ambiente de aprendizado. (M5)

Nos excertos acima, depreendemos que o laboratório não é apenas entendido como relacionado às ciências de referência ("método científico"), mas fundamentalmente como um local de aprendizagem ("diversifica a aprendizagem”), ou seja, uma compreensão de que não existe uma única forma de aprender no laboratório didático. Um último aspecto diz respeito ao papel do laboratório de "pesquisar e elaborar materiais didáticos para as aulas” (M7), que parece apontar o espaço como um lugar de criação que mais se aproxima da Visão II, diferente de uma visão de comprovação e de demonstração presente em outras respostas, que mais se aproximam da Visão I no eixo de análise da natureza da ciência e o laboratório.

Já em relação ao eixo de análise da visão de pedagogia, do ensino e da aprendizagem, esteve presente em todas as respostas tanto uma perspectiva mais construtivista, como no exemplo anterior, que guarda relação com a Visão II desse eixo, e, em igual posição, identificamos também a forma comportamentalista (Visão I), como em M3: "para reforçar ou apresentar um conteúdo para os alunos". A ideia de reforço está presente nas visões behavioristas apoiadas num ensino de transmissão, sob uma perspectiva de apoio e de ajuda. No entanto, essa resposta inclui a ideia de apresentar um conteúdo (teoria), aproximando-o da prática, o que envolve a relação dialética entre essas dimensões do conhecimento, caracterizando-se como uma resposta híbrida (Visão I + II) em relação ao eixo teórico da visão do processo de ensino e aprendizagem.

Outros aspectos, ainda relacionados à visão de ensino e aprendizagem, dizem respeito às possibilidades trazidas nas respostas dos mestrandos sobre o papel do laboratório, tais como o facilitador, o motivador, o potencializador, segundo uma concepção de ludicidade, conforme exemplificam os excertos abaixo.

Acredito que as atividades práticas podem ser motivadoras da aprendizagem, a partir do momento em que elas materializam a abstração dos conteúdos. (M1)

Ao professor auxilia na construção de conhecimento junto ao aluno, adequando a linguagem das ciências e contextualizando. (M2)

Tornar a aprendizagem mais palatável para os alunos. [...] Ou seja, potencializar uma aprendizagem com outras ferramentas de abordagem além das tradicionais. (M6)

Estimulam o interesse, facilitam a compreensão, possibilitam a aproximação maior à ciência. (M5)

Neles, identificamos a preponderância da Visão I do terceiro eixo teórico de análise (Quadro 1) em relação ao papel das atividades prático-experimentais na medida em que os mestrandos valorizam aspectos mais relacionados à sensação e à percepção dos alunos e menos, ao lógico, ao pensante, ao racional. No entanto, também foi 
possível identificar os que relacionam as atividades de laboratório com a forma mais racional de aprendizagem, tal como nos exemplos a seguir.

O aluno entende melhor os métodos científicos e diminui a abstração de determinadas ciências. (M2)

Consolidar o conhecimento teórico sob a ótica contemporânea. (M4)

Há, ainda, os que entendem o laboratório didático de ciências como o lugar de celebração da ciência, mesmo que não fique claro como se dá essa aproximação, uma vez que não é feita distinção entre o laboratório didático escolar e o laboratório de pesquisa científica.

Quando perguntados sobre que tipos de atividades podem ser desenvolvidas no laboratório, as respostas dos mestrandos evidenciaram variações até para um mesmo sujeito, caracterizando hibridismo na concepção dele sobre a epistemologia da ciência. Exemplificamos esse aspecto por meio da resposta de M1, que considera tanto as atividades de cunho investigativo como as de cunho comprobatório.

Investigação, como por exemplo, em laboratórios de química orgânica, onde partindo de uma amostra conhecida, digo, como composição desconhecida e sugerindo marchas analíticas pré-determinadas determinar sua composição. Comprobatórias, isto é, determinado conteúdo como se uma reação química ocorre ou não. (M1)

Um mestrando foi o único a trazer uma visão plural acerca das atividades possíveis de serem realizadas no laboratório didático, como "experimentações, ilustrações, apresentação de vídeos, jogos educacionais, teatro etc.” (M6). Essa resposta inclui um conjunto de atividades prático-experimentais próximo ao que a literatura acadêmica tem entendido como seu papel didático-pedagógico e da qual comungam e advogam Pereira e Moreira (2017).

\section{CONSIDERAÇÕES FINAIS}

Embora os aspectos da Visão I estivessem mais presentes nas respostas dos mestrandos, percebemos ambivalências e contrapontos que apontam para formas não tão universalistas de se entender a ciência. Mesmo na Visão II, que contempla a pluralidade de métodos científicos, o caráter investigativo da ciência e a visão construtivista do ensino e aprendizagem aparecem frequentemente mesclados com concepções que caracterizam a Visão I (indutivismo, método científico único, visão comportamentalista do ensino, ludicidade). Assim, não é possível indicar, entre os sujeitos desta pesquisa, um grupo com visão mais consistente sobre as relações entre natureza da ciência e laboratório, processo de ensino e aprendizagem, e papel das atividades prático-experimentais.

Dessa forma, como principal resultado da pesquisa, destacamos o caráter híbrido em todos os três eixos de análise - a natureza da ciência e o papel do laboratório, a visão de ensino e aprendizagem e o papel pedagógico das atividades prático-experimentais. Nesse sentido, nos parece importante aprofundar o debate acerca dessas questões já nos cursos de formação inicial de professores (licenciaturas), buscando entender melhor a relação entre a teoria e a prática, a questão da teoria preceder a prática, o papel de sensibilização das atividades prático-experimentais e o binômio concreto/abstrato na sua relação com a construção do saber científico. 


\section{REFERÊNCIAS}

FAIRCLOUGH, N. Discurso e mudança social. Brasília: Universidade de Brasília, 2001.

LUNETTA, V. N.; HOFSTEIN, A.; CLOUGH, M. P. Learning and teaching in the school science laboratory: an analysis of research, theory, and practice. In: ABELL, S. K.; LEDERMAN, N. G. (Ed.) Handbook of Research in Science Education. New Jersey: Routledge, 2007.

MACEDO, E. A imagem da ciência: folheando um livro didático. Educação \& Sociedade, v. 25, n. 86, 2004.

MARANDINO, M.; SELLES, S. E.; FERREIRA, M. S. Ensino de Biologia: histórias e práticas em diferentes espaços educativos. São Paulo, SP. Cortez, 2009.

PEREIRA, M. V.; MOREIRA, M. C. A. Atividades prático-experimentais no ensino de física. Caderno Brasileiro de Ensino de Física, v. 34, n.1, 2017.

SILVA, M. G. L.; MOHR, A.; ARAÚJO, M. F. F. de (Org.). Temas de ensino e formação de professores de ciências. Natal: EDUFRN, 2012.

ZIMMERMANN, E. Modelos de pedagogia de professores de física: características e desenvolvimento. Caderno Brasileiro de Ensino de Física, v. 17, n.2, 2000. 